\title{
Transliteracias: A Terceira Onda Informacional nas
}

\section{Humanidades Digitais}

\author{
Brasilina Passarelli \\ Universidade de São Paulo, Escola de Comunicações e Artes, São Paulo, SP, Brasil \\ linapass@aguia.usp.br \\ Ana Claudia Fernandes Gomes \\ Universidade de São Paulo, Escola de Comunicações e Artes, São Paulo, SP, Brasil \\ anaclaufg@gmail.com
}

DOI: https://doi.org/10.26512/rici.v13.n1.2020.29527

Recebido/Recibido/Received: 2019-12-26

Aceitado/Aceptado/Accepted: 2020-03-08

Resumo: A partir do conceito de "ondas informacionais" cunhado por Brasilina Passarelli para representar os diferentes momentos históricos de acesso à Internet, apropriação, produção de conteúdos digitais interativos nas literacias de mídia e informação, participação, compartilhamento até chegar à conectividade contínua e às transliteracias, o objetivo central deste artigo consiste na construção teórica das três ondas informacionais propostas pela pesquisadora e suas relações com especialistas no tema. Passarelli (2010) distinguiu, inicialmente, duas "ondas informacionais" na sociedade em rede: a primeira cujo núcleo central foi definido pelas preocupações políticas e programas de acesso para inclusão digital; a segunda concentrava-se nas diferentes formas de apropriação e produção de conhecimentos na Web a reboque das literacias de mídia e informação. Atualmente vivenciamos o imbricamento da internet das coisas, big data e inteligência artificial e, a reboque desta nova ecologia das redes emerge uma "terceira onda informacional" protagonizada pelo conceito das transliteracias, que abarca as interações entre humanos e não-humanos, recria formas de sociabilidade e rompe os limites da rede, alastrando-se por todas as esferas da vida social contemporânea.

Palavras-Chave: ondas informacionais. literacias de mídia e informação. transliteracias. produção de conteúdo. internet. conectividade contínua.

\section{Transliteracies: The Third Information Wave in Digital Humanities}

Abstract: Based upon the concept of informational waves developed by Brasilina Passarelli to represent different historical moments related to Internet access, appropriation, interactive content production due to media and information literacy development, participation, sharing of information until nowadays continuous connectivity to trans literacy, this article objective is to build a theoretical approach to information waves in relation to other specialists on the issue. Passarelli (2010) proposed, initially, two informational waves at the network society: the very first one based on providing access to the Internet to avoid digital divide; the second one relying on media and information literacy (MIL) to produce multimedia Web knowledge. Nowadays we live the convergence of loT, big data and Al and due to this contemporaneous scenario emerges the "third informational wave" with the concept of trans literacy considering interactions among humans and non- humans, developing a rebirth of sociabilities and causing a disruption on the network limits so far spreading itself throughout all social life spheres.

Keywords: informational waves. media and information literacy. trans literacy. web content production. continuous connectivity.

Transliteracias: la Tercera Onda Informacional en las Humanidades Digitales

Resumen: A partir del concepto de "ondas informacionales " propuesto por Brasilina Passarelli para representar los diferentes momentos históricos del acceso a Internet: apropiación, producción de 
contenidos digitales interactivos con literacias de media e información, participación, compartiendo hasta la conectividad continua actual y a las transliteracias, este trabajo tiene por objetivo la construcción teórica de las tres ondas informacionales propuestas por la investigadora y su relaciones con especialistas otros del tema. Passarelli (2010) distinguió, inicialmente, dos "ondas informacionales" en la sociedad en red: la primera centralizada em políticas públicas de acceso a la Internet para superar la brecha digital; la segunda concentraba-se en las diferentes formas de apropiación y producción de conocimientos em la Web con las literacias de media e información. Actualmente vivenciamos el solapamiento de la Internet de Cosas (IoT), big data e inteligencia artificial y, como resultado esta nova ecología de las redes emerge una "tercera onda informacional "protagonizada por el concepto de transliteracias, que considera las interacciones entre humanos y non humanos, recría formas de sociabilidades y rompe los límites de la red, alastrando-se por todas las esferas de la vida social contemporánea.

Palabras-Clave: ondas informacionales. literacias de media e información. transliteracias. producción de contenidos. internet. conectividad continua.

\section{Utopias e Distopias nas Humanidades Digitais}

Como trabalho final da disciplina de Pós-Graduação intitulada Novas Lógicas e Literacias Emergentes no Contexto da Educação em Rede, que ofereço no PPGCOM/ECA/USP desde 2012, anualmente, os alunos devem construir um texto coletivo sobre vertentes estruturantes da Cultura Digital. Em 2019 eu apresentei a eles minhas reflexões sobre a Terceira Onda Informacional nas Humanidades Digitais, uma vez que em artigos anteriores já publicados eu havia identificado duas ondas informacionais a reboque das tecnologias então preponderantes. Ao longo da disciplina eles propuseram realizar um breve estado da arte com os autores indicados na bibliografia da disciplina a fim de promover um diálogo com as minhas proposições e, também, desenvolveram um jogo interativo tendo as três ondas como tema central. Este artigo apresenta minhas reflexões sobre o tema incorporando as contribuições dos alunos apresentadas no trabalho final da disciplina.

O lançamento da Internet - a rede das redes -na última década do século XX eclodiu como um Big Bang sócio, econômico, tecnológico e cultural que desencadeou, nas duas primeiras décadas do século XXI um tsunamia inundar a vida dos terráqueos em todas as suas dimensões. Este mar infinito de informações trouxe consigo a possibilidade da conectividade contínua, da horizontalização das relações sociais, da interatividade instantânea, da desintermediação, da hibridização de saberes e práticas, da mobilidade e do compartilhamento das ações comunicacionais que, a reboque da citada revolução não mais comporta a dualidade emissor-receptor do século passado.

A reciprocidade das ações comunicacionais do futuro agora imerso na tecnologia digital institui novos modelos de negócios, novas práticas, alicerçando os desafios da reconfiguração das relações sociais e sugerindo a substituição do conceito do usuário passivo para o navegador - produtor (Toffler sugeriu prosumer (aquele que produz e consome simultaneamente). A onipresença de atores em rede (LATOUR, 2005) constituem solo fértil 
para o surgimento de novas lógicas, novas semânticas e novas literacias (conjunto de habilidades e/ou competências construídas a reboque do uso de diferentes tecnologias) no universo da recém-criada cultura digital também denominada cultura do remix, pois contempla novas formas de produção, de consumo e disseminação da informação.

Em cerca de 70 anos - a partir dos grandes computadores do pós - segunda guerra mundial até hoje - a tecnologia digital vem aos poucos redesenhando conteúdos e formas nos territórios do conhecimento tradicional dividido em grandes áreas como ciências da saúde, ciências duras e tecnologia, ciências sociais e humanidades. A reboque das redes de comunicação e recursos digitais de hardware e software emergem áreas revisitadas com saberes híbridos que combinam a tecnologia digital, novos métodos, novas práticas, novas formas de produção e consumo do conhecimento, tanto no universo acadêmico como no mercado de trabalho, a exemplo das Humanidades Digitais.

Desta forma as Humanidades Digitais representam um amplo campo de pesquisa e ações contemplando não somente o uso de métodos digitais nas artes e humanidades em colaboração com cientistas da computação, mas também o modo no qual as artes e humanidades oferecem diferentes"insights" no contexto social e cultural. Desta forma as Humanidades Digitais têm um caráter fortemente colaborativo necessitando de um conjunto variado e diferenciado de literacias (competências), conteúdos e especialidades.

Textos, imagens, vídeos curtos, animações, memes são produzidos e distribuídos instantaneamente em plataformas digitais de redes sociais (Facebook, Twitter, Tik Tok). A juventude adere rápido e massivamente seguida por pais e empresas. Emerge,assim, uma nova ecologia das redes inaugurando um novo conceito de Self - onde uma pessoa pode ter várias Personas. Instaura-se a supremacia da imagem sobre as palavras; o acesso à informação tornase peça estruturante da e-cidadania e inaugura a cultura do Open: código aberto, acesso aberto a dados e informações a todos os cidadãos. Por outro lado, também, surgem questões de segurança dos dados cadastrais dos participantes das plataformas digitais e suas redes sociais. Vazamentos massivos destes dados levam governos a instituir novas políticas publicas de acesso e privacidade de dados. Neste mar de abundância de informação a quantidade supera a qualidade propiciando o fortalecimento das Fake News - narrativas alternativas a fatos estabelecidos.

Este universo paralelo de realidade digital pede novas formas de licenças de propriedade intelectual. Surgem as licenças copyleft em contraposição aos direitos autorais do copyright. A figura do autor individual é esfumaçada pela emergência dos coletivos de produção de conteúdos digitais.A última década do século $X X I$ acolhe o imbricamento da Internet das Coisas (IoT), com a possibilidade de gestão de grandes quantidades de dados 
denominada Big Data e sua interface com a Inteligência Artificial cada vez mais sofisticada e popular.

"Navegar é preciso, viver não é preciso", a célebre frase de Camões em Os Lusíadas traduziu os desafios das Grandes Navegações nos séculos XV e XVI. As conquistas dos mares e territórios garantiriam o poderio econômico e político das Nações, além do conhecimento do espaço geográfico mundial. Séculos depois, as metáforas dos mares e das navegações ainda estão presentes para representar o "mar informacional", o fluxo contínuo de informações trazidas pelas revoluções tecnológicas e pela consolidação da sociedade conectada em rede. E, assim como os antigos navegadores, também temos o desafio cartográfico de mapear a rede e todas as transformações promovidas por humanos e não-humanos conectados, em uma configuração de big data, inteligência artificial, trans humanismo e pós-humanismo. Utopias e distopias em convergência tecendo o agora e os devires.

\section{Primeira onda informacional - Web 1.0,E-mails, Cibercultura e Inclusão Digital}

Em "Os meios de comunicação como extensão do homem", publicado em 1964, McLuhan apresentou como tese central o discurso de que todas as tecnologias são extensões do sistema físico e nervoso humano. O autor destacou-se também na análise sobre o efeito físico e mental das novas tecnologias inseridas na rotina dos homens, reiterando que qualquer invenção ou tecnologia é uma extensão ou auto amputação de nosso corpo. Por essa razão, essa extensão exige novas relações e equilíbrios entre os demais órgãos e extensões do corpo. As reflexões do autor sobre o meio informacional e o volume de informações convergem com a realidade atual:

A velocidade elétrica mistura as culturas da pré-história com os detritos dos mercadologistas industriais, os analfabetos com os semiletrados e os pósletrados. Crises de esgotamento nervoso e mental, nos mais variados graus, constituem o resultado, bastante comum, do desarraigamento e da inundação provocada pelas novas informações e pelas novas e infindáveis estruturas informacionais (MCLUHAN, 1964, p. 336).

Para o autor, o ambiente social produzido pelo homem como extensão de seu corpo responderia às novas pressões e irritações lançando mão de novas extensões, sempre no esforço constante de manter a energia permanente, a constância, o equilíbrio e a homeostase. Como se pode observar, a relevância dos estudos de McLuhan advém não somente pela questão da antecipação de futuro, mas também pela profundidade na qual o autor analisa o componente tecnológico em interação com o ser humano e seus possíveis efeitos sociais. No entanto, é preciso esclarecer que as construções teóricas de McLuhan tiveram como base hipóteses e especulações, 
já que ainda não existia a rede mundial de computadores para um estudo empírico dessa temática.

A Internet foi lançada comercialmente em 1994 introduzindo o conceito de web 1.0, isto é, quando se usava a internet basicamente como fonte de consulta para encontrar dados disponibilizados por sites de empresas e instituições, e também para a comunicação via e-mail. Nesta época, o usuário em rede era apenas um mero espectador da informação, sem nenhum tipo de interferência no fluxo informacional disponibilizado em rede ou qualquer tipo de participação ativa na produção de conteúdos online. Nesse sentido, a Web 1.0 se caracterizava também como a Web das publicações eletrônicas feitas por especialistas da área da tecnologia da informação para os demais usuários, já que para criar uma página na web era necessário ter conhecimento da lógica de programação, até então restrita a estudiosos e profissionais da área, tais como designers, programadores e empresas donas de portais e sites.

Os meios de comunicação via rede ainda eram entendidos como uma extensão dos meios tradicionais de comunicação, tais como rádio, jornais impressos e TV. A novidade foi transferir para o e-mail as comunicações antes realizadas por carta ou telefone, tanto para uso pessoal quanto para uso corporativo, essa ferramenta passou a fazer parte do repertório cultural e comunicacional da sociedade conectada em rede.

Mesmo sob os limites restritos de interação e produtividade da web 1.0, inegavelmente foram ampliadas as fontes de conhecimento, e o distanciamento entre as pessoas passou a ser determinado, não pela localização geográfica, mas pelo grau de interação existente entre o indivíduo e o computador.Conectando com a importância da inclusão digital, para Latour (1994), a modernidade é irreversível, mas ela traz consigo crenças antigas e limitantes, isto é, trata-se de um contexto generalizado no qual todos são obrigados a entrar, ainda que nem todos sejam modernos. Assim como o binarismo tecnológico que combina 0 e 1 , a modernidade separa humanos de não-humanos.

\footnotetext{
"Em rede", o mundo moderno, assim como as revoluções, permite apenas prolongamentos de práticas, acelerações na circulação dos conhecimentos, uma extensão das sociedades, um crescimento do número de actantes, numerosos arranjos de antigas crenças. Quando olhamos para elas "em rede", as inovações dos ocidentais permanecem reconhecíveis e importantes, mas não há o bastante aí para se construir toda uma história, uma história de ruptura radical, de destino fatal, de tristezas ou de felicidades irreversíveis (LATOUR, 1994. p. 52).
}

Em 1996, Castells publica o livro A sociedade em rede no qual, com base em pesquisas, lança reflexões sobre a dinâmica econômica e social da nova era da informação. Castells (1999) ressalta que "o dilema do determinismo tecnológico é, provavelmente, um problema infundado, 
dado que a tecnologia é a sociedade, e a sociedade não pode ser entendida ou representada sem suas ferramentas tecnológicas."

Assim, quem não detinha o conhecimento e a literacia necessários para interagir no mundo em rede não fazia parte da sociedade civil e global. $\mathrm{O}$ autor, parafraseando um dos principais historiadores de tecnologia, Melvin Kranzberg, traz a questão de que "A tecnologia não é nem boa, nem ruim e também não é neutra", nos convocando a pensar sobre a produtividade e a competitividade na produção informacional e para quem haverá ganhos em termos políticos, econômicos e sociais. Em seu livro "A galáxia da internet: reflexões sobre a Internet, os negócios e a sociedade.", compartilha que:

"A era da internet foi aclamada como o fim da geografia. De fato, a internet tem
uma geografia própria, uma geografia feita de redes e nós que processam o
fluxo de informação gerados e administrados a partir de lugares. Como a
unidade é a rede, a arquitetura e a dinâmica de múltiplas redes são as fontes de
significados e função para cada lugar." (CASTELLS, 2003 p. 170)

Para o autor, a criação da internet trouxe a comunicação horizontal caracterizada pela comunicação de cidadão para cidadão, o que ele denominou de "mass self-communication" na qual cada um tem a liberdade de criar a sua forma de se comunicar, não dependendo dos meios de comunicação de massa. Uma das consequências evidentes desse novo ambiente comunicacional é a transformação das relações de poder, que durante a nossa história comunicativa é certamente um dos instrumentos mais importantes para o exercício do poder e contrapoder atuando fortemente na dominação e mudanças sociais. Desse modo, os detentores do poder já buscam formas de participar da comunicação horizontal para contrapor o ganho de voz dos cidadãos comuns:

"A emergência da mass self-communication oferece um meio extraordinário para os movimentos sociais e rebeldes individuais na construção de suas autonomias e confronta as instituições da sociedade sobre seus próprios termos e seus projetos". (CASTELLS, 1999, p. 249).

Em 2001, o semioticista Steven Johnson lança a obra Cultura da interface e anuncia no subtítulo o enfoque em "como o computador transforma nossa maneira de criar e comunicar". Na introdução, refere-se a McLuhan e afirma que "a aceleração tecnológica não nos traria necessariamente satisfação, ele afirmou, mas traria compreensão (...) esse foi o grande legado da velocidade elétrica" (2001, p. 11). Como estudioso da interface, nos traz a definição:

Mas, afinal, que é exatamente uma interface? Em seu sentido mais simples, a palavra se refere a softwares que dão forma à interação entre usuário e computador. A interface atua como uma espécie de tradutor, mediando entre as duas partes, tornando uma sensível para a outra. Em outras palavras, a relação governada pela interface é uma relação semântica, caracterizada por significado e expressão, não por força física. (JOHNSON, 2001, p. 24) 
O autor relaciona a iconografia da interface presente na tela do computador com as interfaces sociais, éticas e estéticas, criadas com o advento da sociedade computadorizada. Sobre a relação homem-computador, Johnson destaca que:

Os seres humanos pensam através de palavras, conceitos, imagens, sons, associações.Um computador que nada faça além de manipular sequências de zeros e uns não passa de uma máquina de somar excepcionalmente ineficiente. Para que a mágica da revolução digital ocorra, um computador deve também representar-se a si mesmo ao usuário, numa linguagem que este compreenda. (JOHNSON, 2001, p. 24)

Para Johnson, a "interface contemporânea" conseguiu reunir arte (inovações criativas) e comércio (apelos de massa), como os "grandes eclipses da experiência cultural de nossos dias, um raro e importante alinhamento de forças, tal como podemos não voltar a ver por muitos anos" (Johnson, 2001, p. 13). E com o olhar para a evolução das interfaces, prevendo claramente os aspectos que serão abordados na "terceira onda", apresenta o conceito de "personalidades digitais" em conjunto com uma narrativa de aproximação entre homem e máquina no sentido de transpor os limites do comportamento maquínico:

O novo paradigma da interface nos aproxima mais do olhar vítreo de Olímpia: em vez de espaço, aqueles zeros e uns são organizados em algo mais próximo de um indivíduo, com um temperamento, uma aparência física, uma aptidão para aprender - o computador como personalidade, não como espaço. Chamamos essas novas criaturas - essas "personalidades" digitais - de agentes. (JOHNSON, 2001, p. 161)

Com o passar dos anos e o aumento exponencial do número de usuários utilizando a web, foi natural que as necessidades dos internautas influenciassem diretamente na maneira como as empresas utilizavam esses recursos e ferramentas. Tais mudanças nas estratégias e comportamento dos, até então, consumidores passivos, fizeram surgir uma nova realidade na internet, cuja principal característica foi a necessidade da interatividade, dando origem à "web $2.0^{\prime \prime}$, oportunizando a fase de criação de conteúdo livre.

O filósofo Pierre Lévy retratou o fenômeno da Internet pela premissa de que "novas maneiras de pensar e de conviver estão sendo elaboradas no mundo das telecomunicações e da informática" (1993, p. 7). As constantes inovações nos dispositivos tecnológicos e informacionais de todos os tipos modificam as relações entre o ser humano, o trabalho e a inteligência (muitas vezes artificial), e o olhar crítico para as alterações sociais passam a ser objeto de pesquisa de muitos estudiosos da área, focando menos no recurso tecnológico (ferramental) e mais nas novas formas de ser e estar no mundo mediado pelas tecnologias. $O$ autor também enxergava a grande potencialidade interativa do ciberespaço:

A comunicação por mundos virtuais é, portanto, em certo sentido, mais interativa que a comunicação telefônica, uma vez que implica, na mensagem, 
tanto a imagem da pessoa como a da situação, que são quase sempre aquilo que está em jogo na comunicação (LÉVY, 2009, p. 81).

Levy desempenhou um papel fundamental na popularização de conceitos fundamentais, tais como cibercultura, inteligência coletiva e ciberdemocracia, marcando o seu discurso sobre as relações entre homens com a mediação das máquinas conectadas em rede. Neste contexto, as palavras visionárias de Lévy, de alguma forma, já antecipavam o que aconteceria com a chegada das mídias sociais presentes na Web 2.0. Para o autor, o ciberespaço é

[...] o espaço de comunicação aberto pela interconexão mundial dos computadores e das memórias dos computadores. Essa definição inclui o conjunto dos sistemas de comunicação eletrônicos (aí incluídos os conjuntos de redes hertzianas e telefônicas clássicas), na medida em que transmitem informações. Consiste de uma realidade multidirecional, artificial ou virtual incorporada a uma rede global, sustentada por computadores que funcionam como meios de geração de acesso (LÉVY, 2009, p. 92).

Motivado pelos mitos e narrativas de criação de um novo mundo, Lévy parafraseia Heráclito ao afirmar que ninguém banha-se duas vezes no mesmo "rio informacional" e afirma que a cibercultura refere-se ao conjunto de técnicas (materiais e intelectuais), atitudes e valores, que tem como "principal operação a de conectar no espaço, de construir e de estender os rizomas do sentido", em um ciberespaço, que é "um imenso ato de inteligência coletiva sincrônica, convergindo para o presente, clarão silencioso, divergente, explodindo como uma ramificação de neurônios" (1999, p. 250).

Para Passarelli (2016), no Brasil, a primeira "onda" informacional ocorreu a partir dos anos 2000, quando a Internet comercial começou a ser ofertada de forma massiva no contexto brasileiro, e as atenções se voltaram majoritariamente às políticas de acesso e fornecimento de infraestrutura para a mitigação dos fenômenos da exclusão digital e para a conquista da cidadania visando prioritariamente a população de baixa renda.

$\mathrm{Na}$ primeira "onda", ocorrida a partir dos anos 2000, quando a Internet comercial começa a ser ofertada de forma massiva no contexto brasileiro, as atenções se voltaram majoritariamente às políticas de acesso e fornecimento de infraestrutura para a mitigação dos fenômenos da exclusão digital e para a conquista da cidadania visando prioritariamente a população de baixa renda. A segunda "onda", intensificada a partir de 2006, veio como decorrência do acúmulo de experiências e de informações advindas das iniciativas públicas e privadas setoriais, as quais criaram as fundações para a necessidade da adoção de novos enfoques e perspectivas de investigação. Estes surgiram preocupados com a reflexão sobre a realidade da apropriação cotidiana das novas tecnologias e na construção de identidades e narrativas pelos atores em rede, em diferentes realidades sócio-históricas e culturais e que desembocam na adoção do conceito de literacias digitais e/ou media literacy para qualificar as novas competências de comunicação, busca de informações e produção de conhecimento dos atores conectados. (PASSARELLI, 2014, p. 3) 
Ao considerar a rede como nova fronteira do pensamento, Latour desenvolve a "teoria do ator-rede" que inclui atores humanos (actor) e actantes não humanos (actants), partindo de estudos antropológicos e construindo narrativas de experiências etnográficas. Metodologia também utilizada nos estudos teórico-metodológicos sobre a sociedade em rede desenvolvidos pelo NACE Escola do Futuro - USP , com destaque para o AcessaSP, programa de inclusão digital, desenvolvido em parceria com o governo do estado de São Paulo, "com cerca de 595 infocentros no estado, 45,5 milhões de atendimentos e 1,9 milhão de usuários cadastrados" (2010, p. 22). Passarelli apresenta indicadores mundiais e locais de conectividade, com destaque para a liderança do Brasil no cenário da América Latina e destaca o programa AcessaSP que permitiu identificar as duas "ondas" da sociedade conectada em rede: a inclusão digital (aprendizado de ferramentas básicas de navegação na web) e a geração de nativos digitais (diferentes formas de apropriação e de produção do conhecimento na web). Em 2007, a etnografia virtual com o público do AcessaSP, indicou e descreveu "dois fenômenos no uso das redes sociais característicos da internet brasileira: o Orkut e a lan house" (2010: 171), referências de formas de sociabilidade, que após uma década, já foram reelaboradas pela sociedade em rede.

\section{Segunda onda informacional: Cultura da Convergência, Cultura Participativa e Literacias de Mídia e Informação}

Em 2006, Henry Jenkins em seu livro Cultura da convergência busca relacionar: convergência dos meios de comunicação, cultura participativa e inteligência coletiva, o que pode ser considerado um "divisor de águas" entre a primeira e a segunda ondas informacionais, propostas por Passarelli. Nessa configuração, os consumidores e os produtores de conteúdos começam a interagir e a convergir criando novas formas de comunicar e viver na sociedade conectada em rede.

O autor ressalta o conceito de continuidade evolutiva das tecnologias, declarando que as velhas mídias não morreram, o que morreu foi a nossa forma de lidar com ela. "Estamos numa época de grandes transformações, e todos nós temos três opções: temê-las, ignorá-las ou aceitálas." Nesse contexto, a cultura da convergência seria o cruzamento das velhas com as novas mídias, construindo uma nova forma de comunicação por meio da produção e da ressignificação dos conteúdos, com uma nova forma de contar e criar histórias, o que o autor chama de narrativa trans mídia.

Na definição de O’Reilly (2005), a Web 2.0 é um conjunto de princípios e práticas que formam um "sistema solar de sites" que demonstram alguns ou todos estes princípios, a uma distância que varia do núcleo. Para o autor, o Google era o melhor exemplo da "Web como 
plataforma", pois fornece serviços cujo uso é pago, direta ou indiretamente, por seus clientes. Assim, a Web 2.0, também chamada de web participativa ou web como plataforma, trouxe os blogs, wikis, chats, as mídias sociais colaborativas, as redes sociais e o conteúdo produzido pelos próprios internautas no conceito de inteligência coletiva, na qual os usuários passam a ser também produtores de conteúdos midiáticos. Jenkins (2009) afirma que as novas mídias possibilitam maior participação e atividade dos indivíduos que, a todo tempo, trocam informações.

A expressão cultura participativa contrasta com noções mais antigas sobre a passividade dos espectadores dos meios de comunicação. Em vez de falar sobre produtos e consumidores de mídia ocupantes de papéis separados, podemos agora considerá-los como participantes interagindo de acordo com o novo conjunto de regras, que nenhum de nós entende por completo. (JENKINS, 2009, p. 30).

Desse modo, juntamente com a possibilidade de produção e publicação em rede, surgem novas formas de ver e produzir cultura, as quais alteram as relações de produção e de consumo. Segundo Passarelli (2010, p. 67), mais do que resultado de uma mudança tecnológica, a convergência das mídias "altera a relação entre tecnologias existentes, indústrias, mercados, gêneros e públicos", modificando "a lógica pela qual a indústria midiática opera e pela qual os consumidores processam a notícia e o entretenimento".

Para Jenkins (2009), a cultura participativa contrasta com a passividade do espectador dos meios de comunicação. Segundo o autor, a convergência ocorre dentro dos "cérebros de consumidores individuais" e em suas interações sociais com os outros. "Cada um de nós constrói a própria mitologia pessoal, a partir de pedaços e fragmentos de informações extraídos do fluxo midiático e transformados em recursos através dos quais compreendemos nossa vida cotidiana" (2009; p. 30).

Ao citar o conceito de "inteligência coletiva" cunhado por Lévy, o autor afirma que o consumo tornou-se um processo coletivo e essa fonte alternativa de poder midiático está presente em nossas interações cotidianas dentro da cultura da convergência. A transformação dos meios de comunicação é mais que uma transformação tecnológica por envolver vários níveis culturais de participação, criação de hábitos e conhecimentos. Jenkins anuncia que "a produção coletiva de significados, na cultura popular, está começando a mudar o funcionamento das religiões, da educação, do direito, da política, da publicidade e mesmo do setor militar," (2009; p. 30) e conclui "enquanto o foco permanecer no acesso, a reforma permanecerá concentrada nas tecnologias; assim que começarmos a falar em participação, a ênfase se deslocará para os protocolos e práticas culturais" (2009; p. 52). Na análise do autor, os anos 90 caracterizaram-se pela busca da interação e os anos 2000 caracterizaram-se pela busca da participação. 
Para O'Reilly (2005), à medida que os usuários adicionam novos conteúdos, estes são vinculados por hiperlinks, formando uma estrutura de teia, semelhante às sinapses no cérebro, com associações mais fortes devido às repetições ou intensidades.Assim, constituem-se como ferramentas a enciclopédia online Wikipedia, baseada na edição de qualquer usuário da Web propondo uma somatória de conhecimentos sobre determinado assunto ou pessoa. Seu uso parecia pouco provável, mas tornou-se uma ferramenta de pesquisa muito utilizada, mesmo que os usuários reconheçam o risco de acessar informações não oficiais ou não verdadeiras. As ferramentas de edição colaborativas possibilitam a produção coletiva de texto e também os fóruns para discussões online.Não é à toa que, em 2006, Você foi eleito como a pessoa do ano pela revista americana Time, em uma homenagem aos milhões de anônimos por sua influência na era global da informação como usuários da internet. A publicação destacou o enorme crescimento e a influência dos conteúdos on-line gerados pelos usuários em blogs ou sites como YouTube, MySpace e Wikipédia.

Na era da informática, das informações livres e da acessibilidade rápida, as tecnologias se renovam, permitindo o contato das pessoas com todos os assuntos, disponíveis a qualquer hora e local. Nesse sentido, Couldry (2010) aponta que:

\begin{abstract}
A digitalização dos conteúdos midiáticos e a normalização, em diversas sociedades, do acesso rápido à Internet, tanto a partir de pontos fixos quanto por meio de aparelhos móveis, significa que, em princípio, todo ponto no espaço é conectado por meio de comunicação mediada para cada outro ponto e essa conexão é sempre potencialmente bidirecional, já que qualquer uma das duas extremidades pode ser remetente ou destinatário (ou os dois). (COULDRY, 2010, p. 51)
\end{abstract}

Após ter trazido a "bússola" orientadora para o paradigma da cultura digital, em Cultura da conexão, de 2014, Henry Jenkins enfoca a lógica social e as práticas culturais que favoreceram e popularizaram as novas plataformas digitais. O autor afirma que com o crescimento da comunicação em rede associada às práticas da cultura participativa, diversas formas de intervenção social consolidam-se.

Novas plataformas criam aberturas para mudanças sociais, culturais, econômicas, legais e políticas, além de constituírem oportunidades para a diversidade e a democratização (...) Os termos dessa participação, todavia, estão ainda por ser definidos e serão formatados por um conjunto de batalhas legais e econômicas que veremos se desenrolar nas próximas décadas (JENKINS, 2014, p. 21)

A transformação da web não significava apenas a ascensão dos indivíduos que produzem e compartilham conteúdo, mas principalmente das próprias plataformas - o YouTube foi comprado pelo Google em 2006 por mais de 1,6 bilhão de dólares e o Facebook se transformou em uma das empresas mais valiosas do mundo. 
Neste contexto de convergência de mídias e cultura participativa Passarelli apresenta os contornos das Literacias de Mídia e Informação (Media and Information Literacy - MIL), conceito defendido pela Unesco a partir de 2008 como um arcabouço teórico para a formação dos professores como agentes de mudança e cidadania digital, "os letrados da sociedade em rede são aqueles capazes de ler, escrever, interagir, comunicar-se por meio dessa linguagem multimídia, reconhecendo as práticas sociais e gêneros textuais que envolvem cada elemento dessa interface" (2010, p. 73). Ainda segundo a autora, "os usuários da modernidade agora, na contemporaneidade, são denominados prosumers (produtor + consumidor) com a consequente redefinição dos papéis desses atores em rede" (2012, p. 14). Em um terceiro artigo, Passarelli enfatiza:

(...) reflexão sobre a realidade da apropriação cotidiana das novas tecnologias e na construção de identidades e narrativas pelos atores em rede, em diferentes realidades sócio-históricas e culturais e que desembocam na adoção do conceito de literacias digitais e/ou media literacy para qualificar as novas competências de comunicação, busca de informações e produção de conhecimento. (PASSARELLI, 2014b, p. 233)

No espectro das Literacias de Mídia espera-se desenvolver habilidades como: pensamento crítico; decifrar as mensagens midiáticas para desestimular atitudes consumistas; reconhecer diferentes versões do mesmo fato; reconhecer as técnicas de persuasão em uso; descobrir partes da história que não estão sendo contadas; avaliar as mensagens midiáticas à luz de nossas crenças e experiências; criar e distribuir nossas próprias mensagens e lutar por justiça na mídia.

No âmbito das Literacias de Informação é importante : conhecer e reconhecer fontes de informação credenciadas e com autoridade reconhecida a exemplo de grandes jornais impressos ou na versão digital; estimular a leitura de diferentes fontes de informação nacionais e internacionais; estar atento ao fenômeno das Fake News e como não se deixar envolver por falsas notícias ou verdades parciais; alertas de cibersegurança e endereços web não oficiais entre outros.

\section{Terceira onda informacional -Conectividade Contínua, Infoesfera e Transliteracias}

De acordo com Van Dijck (2013), a plataformização da sociedade refere-se à relação entre plataformas online e estruturas sociais. Muitos dos setores sociais, seja transporte, saúde, educação ou jornalismo, têm se tornado quase que inteiramente dependentes das infraestruturas digitais disponibilizadas pelas cinco grandes empresas de plataformas digitais americanas: Google (Alphabet), Amazon, Facebook, Apple e Microsoft.A autora defende que as plataformas são um ecossistema que não deve ser analisado apenas no nível micro, pois sua interoperabilidade 
reforça tanto seu poder quanto seu alcance. Assim, a plataformização leva a uma mudança na qual as empresas deixam de pensar no controle dos recursos, e passam a atuar como organizadoras destes, como Uber, Airbnb entre outros.

Nesse contexto de plataformização, os dados dos usuários passam pelo processamento algorítmico e são transformados em mercadorias. Desse modo, a problemática reside nos processos sociais e econômicos ocultados nos algoritmos, nos modelos de negócios e nos fluxos de dados que não são regidos pelo controle democrático para assegurar, minimamente, a estabilidade de toda a cadeia de trabalho. Este fato ocorre por não termos, ainda, uma legislação clara em relação às condições de trabalho em uma sociedade, cada vez mais, desintermediada.

É importante ressaltar que Levy foi um dos primeiros estudiosos a contribuir com a tese de que a "desintermediação", ou o fim de intermediários e mediadores, seria inerente ao crescimento das redes digitais, afirmando que "o surgimento do ciberespaço cria uma situação de desintermediação, cujas implicações políticas e culturais ainda não terminamos de avaliar" (LÉVY, 1998). Apesar dos 20 anos que separam a escrita de Lévy sobre a desintermediação e a nossa atualidade, o conceito de que os mediadores seriam cada vez mais suprimidos, continua em voga e o autor é citado em diversos estudos recentes, sendo referência em temas como hipertextos, internet e sociedade. As suas obras trouxeram reflexões importantes sobre os impactos da tecnologia nas formas de pensar, agir e se comunicar em uma sociedade mediada internet.

Como a informação "representa o principal ingrediente de nossa organização social, e os fluxos de mensagens e imagens entre as redes constituem o encadeamento básico de nossa estrutura social" (CASTELLS, 2006, p. 573), é o conhecimento que move a economia criativa, com a constante inovação tecnológica e a sobreposição das tecnologias antigas.

As mudanças incorporadas à web 3.0 são ainda mais significativas. Aqui, os aprimoramentos na organização e sistematização das informações disponíveis tornam os resultados mais precisos. Surge, então, o conceito da web semântica, que inaugura um processo mais complexo na utilização da ferramenta. A World Wide Web (rede mundial) se tornaria a World Wide Database (base de dados mundial), isto é,um mar de dados em que programas entendam como fazer o melhor uso desses dados por meio da inteligência artificial (IA) e do machine learning (máquinas que aprendem). Do ponto de vista dos internautas, a organização dos conteúdos e informações por IA significa que os programas serão capazes de melhor entender as necessidades individuais, fornecendo um conteúdo personalizado, seja ele uma notícia, um diagnóstico, um site de pesquisa, uma loja ou até mesmo uma propaganda.

Diante desse novo cenário, os internautas tendem a passar mais tempo conectados e inserir a internet em diferentes aspectos de suas vidas: seja para o estudo, o entretenimento, o 
ato de fazer compras, o pagamento de contas via Apps, a pesquisa, a consulta da previsão do tempo, entre outros. Neste contexto, o termo onlife, cunhado por Floridi (2015), é utilizado para referir-se ao novo paradigma das experiências humanas que transcende o conceito de vida online e offline.

No mundo onlife, os artefatos deixaram de ser meras máquinas simplesmente operando de acordo com instruções humanas. Eles podem mudar as situações de maneira autônoma e podem fazer isso explorando a riqueza exponencialmente crescente de dados, que estão cada vez mais disponíveis, acessíveis e processáveis pelo desenvolvimento rápido das TICs. Os dados são gravados, armazenados, computados e retornados em todas as formas de máquinas, aplicativos e dispositivos de maneiras inovadoras, criando infinitas oportunidades para ambientes adaptáveis e personalizados. Filtros de vários tipos continuam a corroer a ilusão de uma percepção objetiva e imparcial da realidade ao mesmo tempo em que abrem novos espaços para interações humanas e novas práticas de conhecimento. (FLORIDI, 2015, p. 10, tradução nossa)

Luciano Floridi é um filósofo italiano atualmente diretor do Oxford Internet Institute, que busca compreender, a partir de perspectiva transdisciplinar, o papel da informação no tempo contemporâneo. Em seu livro The fourth revolution (2014) defende a necessidade da reconfiguração da vida social afirmando: a primeira revolução foi a da agricultura, que trouxe o sedentarismo como opção ao nomadismo; a segunda revolução foi a industrial, que trouxe as máquinas como opção ao trabalho manual; a terceira revolução foi a cognitiva psicanalítica, que trouxe os conceitos de self e autoconhecimento para a compreensão do indivíduo; e a quarta revolução trouxe as tecnologias digitais como opção para a reinvenção do humano e das relações sociais na Infoesfera. Afirma também que numa época de hiper conectividade não há mais separação possível entre estar conectado e desconectado das redes digitais, fato que altera as relações econômicas, sociais, culturais e até mesmo políticas.

O cientista da computação americano e ativista digital Jaron Lanier (2010) responsável por divulgar um pensamento contra cultural em relação às redes sociais, que alteram a produção de valores (econômicos, sociais, políticos e simbólicos) e demandam análises críticas que superam as discussões sobre os avanços tecnológicos. Ele critica o fato de como a web generaliza conhecimentos e pessoas, isto é, a maneira massiva como a internet influencia os hábitos individuais estimulando o protagonismo dos coletivos em detrimento do indivíduo e engrossa a corrente de pensamento sobre as distopias da Internet

Quando os desenvolvedores das tecnologias digitais projetam um programa que requer que você interaja com um computador como se ele fosse uma pessoa, eles pedem que você aceite, em algum canto de seu cérebro, que você também pode ser visto como se fosse um programa. Quando projetam um serviço da Internet editado por uma imensa multidão anônima, eles estão sugerindo que uma multidão aleatória de pessoas é um organismo com um ponto de vista legítimo. Diferentes designs de mídia estimulam diferentes potenciais da 
natureza humana. Não deveríamos buscar fazer o comportamento de manada ser o mais eficiente possível. Em vez disso, deveríamos buscar inspirar o fenômeno da inteligência individual. (LANIER, 2010, p. 19)

Para o autor, a internet modificou, de maneira veloz, a vida cotidiana para sempre, e continuará a fazê-lo cada vez mais, com o avanço da tecnologia dos meios de comunicação. Segundo ele, os aparatos tecnológicos se tornaram extensões dos humanos, assim como antevisto por McLuhan, e por isso, podem manipular opiniões e processos culturais.

\begin{abstract}
Criamos extensões para o ser, como olhos e ouvidos remotos (webcams e telefones celulares) e memória expandida (o mundo de detalhes que você pode encontrar on-line). Essas extensões se tornam as estruturas por meio das quais você se conecta ao mundo e a outras pessoas. Essas estruturas, por sua vez, podem mudar a forma como você vê a si mesmo e ao mundo. Nós aprimoramos a sua forma de pensar por manipulação direta da sua experiência cognitiva, não indiretamente, pela argumentação. Basta um pequeno grupo de engenheiros para criar uma tecnologia capaz de moldar todo o futuro da experiência humana com uma incrível velocidade. (LANIER, 2010, p. 22)
\end{abstract}

Luc Ferry filósofo contemporâneo francês (2018) identifica esse momento como a terceira revolução industrial, a qual é caracterizada pela NBIC (nanotecnologia, biotecnologias, informática - big data e internet das coisas, cognitivismo - inteligência artificial). Além desses aspectos ele ressalta ainda a necessidade de acrescentar as impressoras 3D, que podem imprimir tecidos biológicos; a robótica, pesquisa sobre as células-tronco induzidas e a hibridação entre o homem e a máquina.Mesmo relatando esses oito aspectos Ferry ressalta que o "coração do coração é a IA", a qual está na base de duas consequências maiores da terceira revolução industrial.A primeira consequência é o que se chama de economia colaborativa, cujo verdadeiro modelo é o Airbnb e o Uber onde a IA trata dos dados, os big data, em alguns décimos de segundos. Essa nova economia, simbolizada por essas empresas caracteriza-se por não profissionais poderem entrar em concorrência com profissionais graças à IA.

A segunda consequência é o projeto trans humanista que se apoia na engenharia genética, cujo desenvolvimento, particularmente no sequenciamento do genoma, deve-se à IA e ao famoso Crispr-Cas9, a ferramenta de edição do DNA. Mas esse projeto é alimentado, também, pela hibridação homem-máquina, pela pesquisa sobre as células-tronco multipotentes, que permitirá a medicina reparadora. Empresas como a Google investe bilhões de dólares no projeto de aumento da longevidade humana. O trans humanismo é visto por Ferry como uma nova ideologia, "uma corrente cada vez mais poderosa, apoiada pelos gigantes da web, a exemplo do Google" (2018, p. XXVIII). 
Após duas décadas da publicação de Cibercultura de Pierre Lévy, o comunicólogo Teixeira Coelho publica em 2019, E-cultura, a utopia final e analisa a interação entre inteligência artificial e humanidade. Segundo Coelho:

(...) uma cultura, claro, não surge, não emerge abruptamente. Um vulcão pode explodir "de repente" (...) A diferença entre esta cultura que se ergue, a eCultura, e um vulcão é que ela não deixa espaço para onde se possa correr em busca de abrigo.( COELHO, 2019, p. 9).

A inexorabilidade do processo cultural percorre toda a narrativa e após a referência ao vulcão em erupção que se aproxima do dilúvio de Lévy, o autor também utiliza a metáfora da estrada ao afirmar que "as rotas a percorrer estão pavimentadas por boas intenções e poucas indicações concretas sobre como encontrar a saída. A IA é o monólito misterioso, aparentemente poderoso" (2019, p. 239).

Para Nick Bostrom (2005), um estudioso da inteligência artificial e crítico sobre os riscos de ficarmos cada vez mais submetidos a uma inteligência maquínica, caracteriza o trans humanismo como o processo no qual a natureza humana pode ser aprimorada através do uso da ciência aplicada e de outros métodos racionais, que podem aumentar a longevidade da vida humana, estender as nossas capacidades físicas e intelectuais e nos dar um maior controle sobre os nossos estados mentais e humores. E nos traz que:

As tecnologias em questão incluem não apenas as atuais, como a engenharia genética e a tecnologia da informação, mas também antecipações de desenvolvimentos futuros, como a realidade virtual totalmente imersível, as máquinas nanotecnológicas e a inteligência artificial. (BOSTROM, 2005, p. 2)

Os defensores do trans humanismo, pela linha crítica de estudo de Bostrom, acreditam que, embora haja riscos que precisem ser identificados e evitados, as tecnologias de melhoramento humano irão oferecer um potencial enorme para a humanidade. A longo prazo, é possível que tais melhoramentos nos transformem ou aos nossos descendentes, em seres "pós humanos", os quais poderiam ter longevidade, faculdades intelectuais e até emocionais superiores do que as de qualquer ser humano atual.

Em oposição a essa visão trans humanista, tem-se o campo bioconservador que se posiciona contra o uso da tecnologia para modificar a natureza humana. Uma das preocupações centrais dos bioconservadores é a de que tecnologias de melhoramento humano poderiam ser "desumanizantes", podendo aviltar a dignidade humana ou inadvertidamente erodir algo que é profundamente valioso a respeito de ser humano, mas que é difícil de ser colocado em palavras ou de se levar em conta em uma análise de custo e benefício (Bostrom, 2005).

Em sua mais recente publicação, o livro Superinteligência: caminhos, perigos e estratégias para um novo mundo, Bostrom afirma que: 
Diante do prospecto de uma explosão de inteligência, nós, humanos, somos como crianças pequenas brincando com uma bomba, tamanho é o descompasso entre o poder de nosso brinquedo e a imaturidade da nossa conduta. A superinteligência é um desafio para o qual não estamos preparados atualmente e assim continuaremos por um longo tempo. Sabemos pouco a respeito do momento em que a detonação ocorrerá, embora seja possível ouvir um fraco tique-taque quando aproximamos o dispositivo dos nossos ouvidos (BOSTROM, 2018, p. 468).

Por outro lado o historiador Yuval Noah Harari, autor dos bestsellers "Sapiens", "Homo Deus", e "21 lições para o século 21" destaca:

As revoluções na biotecnologia e na tecnologia da informação nos darão controle sobre o mundo interior, e nos permitirão arquitetar e fabricar vida. Vamos aprender a projetar cérebros, a estender a duração da vida e a eliminar pensamentos segundo nosso critério. E ninguém sabe quais serão as consequências disso. Humanos sempre foram muito melhores em inventar ferramentas do que em usá-las sabiamente. (HARARI, 2018, p. 21)

O autor discute questões que envolvem desde a substituição do homem pela máquina em funções decisórias, a liberdade cerceada pelos algoritmos, o poder dos dados entre outros temas que perpassam o incessantemente investimento para que a tecnologia ultrapasse a inteligência humana, sem a visão do que poderá acontecer com uma sociedade na qual o homem perderá o seu protagonismo. $\mathrm{O}$ autor ressalta que "Não obstante o perigo de desemprego em massa, o que deveria nos preocupar ainda mais é a transferência da autoridade de humanos para algoritmos, o que poderia destruir qualquer fé remanescente na narrativa liberal e abrir o caminho para o surgimento de ditaduras digitais".

Em entrevista ao programa Roda Viva da TvCultura em 11/11/2019, disponível em https://youtu.be/pBQM085IxOM, Harari afirma que os dados constituem o novo capital e a responsabilidade da regulamentação de sua utilização é do sistema político. Diante do grande poderio tecnológico, da inteligência artificial e da automação acelerada há necessidade de decisões sobre o uso e o controle dos dados. Além da regulamentação e da necessidade de cooperação global, a educação apresenta-se como um dos grandes desafios do século XXI. Segundo o autor entrevistado, as pessoas continuarão estudando, aprendendo e mudando durante a vida toda porque não se sabe como será o mercado de trabalho dos próximos 30 anos e quais as habilidades que as pessoas precisarão desenvolver.

A reboque da evolução exponencial dos recursos da tecnologia digital no imbricamento da IoT, Big Data e Inteligência Artificial destaco como Terceira Onda Informacional a evolução do conceito de Literacias de Mídia e Informação para Transliteracias - a habilidade de ler, escrever e interagir entre diferentes plataformas digitais, artefatos e meios de comunicação, utilizando desde a oralidade ao desenho, linguagem escrita, mídia impressa, Rádio, Tv, vídeos, filmes e redes sociais. Diante da expansão da centralidade das tecnologias digitais na vida contemporânea 
a UNESCO também propôs, em seu Fórum de 2014 em Paris, ampliar os conceitos de Literacias de Mídia e Informação (MIL) para Transliteracias, entendendo que nesta nova denominação reside o empoderamento da mídia e da informação, tanto em seu aspecto como conteúdo, organização e seus aspectos de tecnologia digital. Desta forma Transliteracia representa a conexão entre diferentes competências e, também, a interação entre diferentes campos de conhecimento, reunindo conhecimento advindos da tecnologia em sua conexão com todas as áreas do conhecimento.

No contexto das distopias que este artigo pretende trazer à luz, em oposição às utopias que a tecnologia pode oferecer como estamos demonstrando, há estudiosos como Morozov (2018) que observam que o controle social feito por meio dos algoritmos nos revela o modelo de capitalismo "dadocêntrico" adotado pelo Vale do Silício, que busca converter todos os aspectos da existência cotidiana em ativo rentável: tudo aquilo que costumava ser o nosso refúgio contra os caprichos do trabalho e as ansiedades do mercado.

Nesse sentido, Doneda e Almeida (2018) nos esclarecem que os algoritmos que antes serviam apenas para compor um conjunto de instruções para realizar uma tarefa programada, tornam-se cada vez mais responsáveis por decisões, avaliações e análises que têm impactos concretos em nossa vida. Já se fala em governabilidade algorítmica:

\begin{abstract}
Já foram identificados na literatura alguns riscos que o uso dos algoritmos pode trazer, tais como manipulação, viés, censura, discriminação social, violações da privacidade e dos direitos de propriedade, abuso de poder de mercado, efeitos sobre as capacidades cognitivas, além de uma crescente heteronomia. É preciso considerar um processo de governança para os algoritmos com vistas a tratar desses riscos. (DONEDA E ALMEIDA, 2018, p. 145)
\end{abstract}

A reflexão sobre os impactos das informações privadas abertamente nas redes, de acordo com a pesquisadora Sibilia (2018) está pautada na lógica "você é o que o Google diz que você é":

Antes da internet, se você era uma má pessoa, podia começar uma nova vida. (...) Como se costumava dizer antigamente, esse indivíduo podia tentar se regenerar. De que modo? Elaborando as próprias experiências passadas para iniciar uma nova etapa vital (...) Mas isso deixou de ser factível porque agora "você é o que o Google diz que você é". (SIBILIA, 2018, p. 199)

Desse modo, as redes sociais, por exemplo, são meros repositórios de dados a serviços de empresas que querem oferecer seus produtos e serviços de forma mais assertivas para os seus clientes, ou seja, alógica do poder das empresas sobre os meios de comunicação digitais volta à pauta fortemente na era digital:

$\mathrm{Na}$ verdade, estamos sendo duplamente ludibriados: quando entregamos os nossos dados - que acabam no balanço dos ativos do Google - em troca de serviços relativamente triviais, e quando esses mesmos dados são utilizados para customizar e estruturar o nosso mundo de maneira pouco transparente e pouco desejável. (MOROZOV, 2018, p. 617) 
O pesquisador britânico Slee em seu livro Uberização: a nova onda do trabalho precarizado, lançado no Brasil em 2017, nos traz uma visão sobre os impactos da economia baseada no compartilhamento, como Uber e Airbnb entre outros. O autor repensa a lógica desmediação e o quanto ela pode ocasionar danos às relações de trabalho e a perda de controle dos órgãos oficiais que regem as leis e normas do país. E, como um passo seguinte à economia baseada no compartilhamento, alega que:

\begin{abstract}
O bitcoin e a promessa das criptomoedas são a próxima onda. Atingindo proporções massivas alguns anos depois da economia de compartilhamento, as criptomoedas invocam visões semelhantes. Não precisamos mais confiar nas grandes instituições. Podemos confiar na tecnologia. Não precisamos confiar no Estado e nas moedas tradicionais. Podemos fazer nossos bitcoins. (SLEE, 2017: 17)
\end{abstract}

\title{
5 A Juventude Brasileira frente aos Desafios do Futuro - Agora
}

Dados da Pesquisa TIC Domicílios Brasil 2018 [https://www.cetic.br/pesquisa/domicilios/] apontam um crescimento de $67 \%$ para $70 \%$ relativo ao acesso da população à Internet, o que equivale a 126,9 milhões de pessoas. A pesquisa TIC Domicílios é realizada anualmente desde 2005 com o objetivo de mapear o acesso à infraestrutura TIC nos domicílios urbanos e rurais do país e as formas de uso destas tecnologias por indivíduos de 10 anos de idade ou mais. A partir de 2013 a TIC Domicílios também incorporou em seu escopo a TIC Crianças, que investiga o uso de TIC entre indivíduos de 5 a 9 anos, e era realizada separadamente desde 2009.A pesquisa, feita anualmente pelo Centro Regional de Estudos para o Desenvolvimento da Sociedade da Informação (Cetic), é uma das principais no país e apresenta entre outros os seguintes destaques:

- Nas regiões urbanas, a conexão é um pouco maior do que a média: $74 \%$ da população está ligada à internet;

- Pela primeira vez, metade da zona rural brasileira está conectada - $49 \%$ da população disse ter acesso à rede em 2018, acima dos 44\% de 2017;

- Também pela primeira vez, metade da camada mais pobre do Brasil está oficialmente na internet: $48 \%$ da população nas classes D e E, acima de 42\% em 2017;

- São 46,5 milhões de domicílios com acesso à internet, $67 \%$ do total;

- Entre os usuários da internet, $48 \%$ adquiriu ou usou algum tipo de serviço on-line, como aplicativos de carros, serviços de streaming de filmes e música, ou pedido de comida

A reboque dos dados acima apresentados pode-se constatar a expansão importante da conectividade a Internet no país protagonizada nos últimos cinco anos pela democratização da 
posse e uso do smartphone ou celular. A penetração do acesso e uso da Internet reforça a importância dos estudos aqui apresentados reiterando a relevância da adoção de políticas públicas que incentivem a implementação das literacias de mídia e informação e transliteracias como plataforma de e-cidadania, desde o ensino fundamental ao terceiro grau, respeitadas os diferentes estágios de desenvolvimento destas populações.

Mais que habilidades cognitivas, as literacias são práticas sociais, que além de demandarem artefatos físicos,tecnologias digitais e conteúdos relevantes, demandam políticas públicas que garantam a inclusão, a produção e fruição dessa cultura digital, e que estejam pautadas nos direitos à educação, ao conhecimento e à informação. A Base Nacional Comum Curricular (BNCC) brasileira a ser implementada em 2019 considera a cultura digital uma das competências fundamentais a serem desenvolvidas no processo educacional, em busca do desenvolvimento da autonomia, protagonismo e pensamento crítico. Projetos educacionais devem ser promovidos nos âmbitos formais, não-formais e informais para a consolidação da cidadania digital.

A hiper conectividade, compreendida como conectividade contínua, abrange os fluxos e refluxos das interfaces de mediação informativas e comunicacionais dos atores em rede (Latour), que configuram as modificações da rede, a qual vitaliza-se ao produzir e direcionar ações. As tecnologias disruptivas que propiciam a emulação cerebral autônoma ou uploads da mente humana para computadores (BOSTROM) coexistem com a nanotecnologia, que gradativamente combate o envelhecimento, as doenças e a morte de uma "raça pós-humana". As dicotomias entre real e virtual, online e offline desaparecem a partir das interações entre máquinas, humanos e natureza em uma revolução da mobilidade (FLORIDI). Nesse sentido, as TIC, mais que ferramentas, apresentam-se como forças ambientais (DI FELICE) de uma era informacional, que exige novas literacias e transliteracias (PASSARELLI) em todas as esferas da vida social. Apresentado como "aprisionamento tecnológico" (LANIER), o caminho traçado, o mapa desenhado, o limite transposto constituem-se diariamente como desafios de navegação em um mar informacional que produz ondas em sua infinitude...

\section{Referências}

BRUNO, F. et al. (org.). Tecnopolíticas da vigilância: perspectivas da margem. São Paulo: Boitempo, 2018.

BOSTROM, N.Em defesa da Dignidade Pós-Humana. Bioethics, v. 19, n. 3,p. 202-214, 2005.

BOSTROM, N. Superinteligência: caminhos, perigos e estratégias para um novo mundo. Rio de Janeiro: Dark Side Books, 2018. 
CAMÕES, L. Os Lusíadas. São Paulo: Saraiva, 2010.

CASTELLI, I. Celular é o maior meio de acesso à web no Brasil. 08 jan. 2014. Disponível em: www.tecmundo.com.br Acesso em: 1 dezembro de 2019.

CASTELLS, M. A galáxia da Internet: reflexões sobre a Internet, os negócios e a sociedade. Rio de Janeiro: Jorge Zahar, 2003.

CASTELLS, M. A Sociedade em Rede. 11. ed. São Paulo: Paz e Terra, 1999.

COELHO, T. E-cultura, a utopia final: inteligência artificial e humanidades. São Paulo: Iluminuras Itaú Cultural, 2019.

COLL, C. Psicologia e currículo: uma aproximação psicopedagógica a elaboração do currículo escolar. São Paulo: Ática; 2000.

COULDRY, N. Does the media have a future? Matrizes, São Paulo, v.4, n. 1, p. 51-64, jul./dez., 2010.

FERRY, L. A revolução transumanista. Barueri, SP: Manole, 2018.

FLORIDI, L. The fourth revolution: how the infosphere is reshaping the human reality. London: Oxford Press, 2014.

FLORIDI, L. (Ed.) The Onlife Manifesto: Being Human in a Hyperconnected Era. London: Springer, 2015.

FULLAN, M. O significado da mudança educacional. Porto Alegre: Artmed, 2009.

HARARI, Y. 21 lições para o século 21. São Paulo: Companhia das Letras, 2018.

HARARI, Y. Entrevista programa Roda Viva . São Paulo: TvCultura, Novembro de 2019. Disponível em: www.youtube.com/rodaviva Acesso em 24 de novembro de 2019.

HUXLEY, A. Admirável mundo novo. São Paulo: Abril Cultural, 1980.

JENKINS, H. Cultura da convergência. 2.ed.São Paulo: Aleph, 2009.

JENKINS, H. Cultura da conexão: criando valor e significado por meio da mídia propagável. São Paulo: Aleph, 2014.

JOHNSON, S. Cultura da Interface: como o computador transforma nossa maneira de criar e comunicar. Rio de Janeiro: Jorge Zahar, 2001.

LANIER, J. Gadget: você não é um aplicativo! São Paulo: Saraiva, 2010.

LATOUR, B. Jamais fomos modernos: ensaio de antropologia simétrica. Rio de Janeiro: Editora 34, 1994.

LATOUR, B. Ciência em ação: como seguir cientistas e engenheiros sociedade afora. São Paulo: Editora UNESP, (1998) 2000. 
LÉVY, P. As tecnologias da Inteligência. O futuro do pensamento na era da informática, Rio de Janeiro: Editora 34, 1993.

LÉVY, P. A revolução contemporânea em matéria de comunicação. Revista Famecos, v. 5, n. 9, p.37-49, Dez. $1998 . \quad$ Disponível em: http://revistaseletronicas.pucrs.br/ojs/index.php/revistafamecos/article/view/3009

LÉVY, P.A inteligência coletiva: por uma antropologia do ciberespaço. 4. ed. São Paulo: Loyola, 2003.

LÉVY, P. Cibercultura. São Paulo: Editora 34, 1999.

LÉVY, P. Cibercultura. 3.ed. São Paulo: Editora 34, 2009.

MCLUHAN, M. Os meios de comunicação como extensões do homem (Understanding media). São Paulo: Editora Cultrix, 1964.

MCLUHAN, M. McLuhan por McLuhan. Entrevistas e conferências inéditas do profeta da globalização. Rio de Janeiro: Ediouro, 2005.

MORAIS, A. M. et al.Um jogo educacional para o auxílio do aprendizado de Geometria Espacial. Disponível em: http://www.lbd.dcc.ufmg.br/colecoes/wie/2009/028.pdf Acesso em: 24 nov. 2019.

MORAN, J. M.; MASETTO, M. T.; BEHRENS, M. A. Novas tecnologias e mediação pedagógica. Campinas, SP: Papirus, 2000.

MORIN, E. O método 2: a vida da vida. Porto Alegre: Sulina/Meridional, 2007.

MOROZOV, E. Big Tech: A ascensão dos dados e a morte da política. São Paulo: Ubu Editora, 2018.

O'REILLY, T. What is Web 2.0: design patterns and business models for the next generation of software. 2005. Disponível em: <http://oreilly.com/web2/archive/what-is-web-20.html>. Acesso em: 9 nov. 2019.

PASSARELLI, B. Literacias emergentes nas redes sociais: estado da arte e pesquisa qualitativa no observatório da cultura digital. In: PASSARELLI, Brasilina; AZEVEDO, José. (org.). Atores em Rede: Olhares Luso-Brasileiros. São Paulo: Editora SENAC, 2010.

PASSARELLI, B.; JUNQUEIRA, A. H. Juventude Conectada. São Paulo: Fundação Telefônica, 2012.

PASSARELLI, B, JUNQUEIRA, A. H., ANGELLUCI, A. C. B, Os nativos digitais no Brasil seus comportamentos diante das telas. Matrizes, v. 8, n. 1, jan./jun., 2014.

PASSARELLI, B. Mediação da informação no hibridismo contemporâneo: um breve estado da arte. Ciência da Informação, Brasília, v. 43, n. 2, 2014b. Disponível em: www.revista.ibict.br Acesso em dez 2019.

PASSARELLI, B. (org.); GOMES, A. C. F.; ENDO, B.; SOBREIRA, E.S.R.; SOLEDADE, R.T. Web Waves: narrativas acadêmicas e o jogo interativo das ondas informacionais. São Paulo: 
PPGCOM/ECA/USP, 2020. Disponível em: <http://novasliteraciasusp.blogspot.com/p/turma2019.html> Acesso em 22/01/2020.

RECUERO, R. Considerações sobre a Difusão de Informações em Redes Sociais na Internet. In: CONGRESSO DE CIÊNCIAS DA COMUNICAÇÃO DAREGIÃO SUL, 8, 2007, Passo Fundo. Anais eletrônicos... Passo $\quad$ Fundo, 2007.2 Disponível em: $<$ http://www.intercom.org.br/papers/regionais/sul2007/resumos/R0464-1.pdf $>$. Acesso em: 9 nov. 2019.

SARTORI, R. Disponível em:<http://www.abepro.org.br/biblioteca/ENEGEP1999 A0351.PDF/> Acesso em: 10 nov. 2019.

SLEE, T. Uberização: a nova onda do trabalho precarizado. São Paulo: Elefante Editora, 2017.

SODRÉ, M. Reinventando a educação: diversidade, descolonização e redes. Petrópolis, RJ: Vozes, 2012.

TIC Domicílios Brasil 2018. CETIC. São Paulo: CETIC, 2019. Disponível em: https://www.cetic.br/pesquisa/domicilios/ Acesso em: dezembro de 2019.

VALENTE, J. A. Aprendizagem ativa no ensino superior: a proposta da sala de aula invertida. 2014. Disponível em: www.pucsp.br > img > aci > 27-8 agurdar proec textopara280814 Acesso em: 4 abr. 2017.

VAN DIJCK, J. The culture of connectivity: A critical history of social media. Oxford: Oxford University Press, 2013. 